\title{
ANALISIS KEKUATAN STRUKTUR REPAIR SKIN DOUBLER PESAWAT B737-300
}

\author{
Djarot Wahju Santoso \\ Prodi Teknik Penerbangan \\ J1. Janti Blok R. Lanud Adisutjipto \\ djarot_wahyu84@yahoo.com
}

\begin{abstract}
Fuselage is a structure of airplane as the location where the passengers and goods as well as to place the wing and other structures. Fuselage gets loading when the aircraft take off flight maneuvers, landing and when at the ground. One is the pressure loading on the fuselage aircraft cabin. In continuous operation airplane due to cabin pressure damage such as cracks often occur in the fuselage. The use of skin doubler to handle cases mainly crack analysis is needed to see the effect doubler thickness and variations in fastener against the structure strength.

In this study doubler skin structure modeling and analysis using sofiware CATIA V5R21. Modeling structures made 4 types of structure to use variations of the number of fastener and three other structures to changes in the thickness of the doubler. The whole model is given tensile load and differential pressure.

Use of doubler thicker in the repair structure will lower the stress that occurs at the doubler. The more number of rows of fastener used will decrease the stress on the fastener this happens to tensile load, but not effective enough for the load pressure differential. Modeling the structure is safe against tensile loading and internal pressure.
\end{abstract}

Keywords: Strength of the structure, Repair, Skin doubler.

\begin{abstract}
Abstrak
Fuselage merupakan struktur pada pesawat sebagai ruang tempat penumpang dan barang juga untuk meletakkan sayap, serta struktur yang lain. Fuselage mengalami pembebanan pada saat pesawat take off, maneuver terbang, landing dan pada saat di darat. Salah satu pembebanan pada fuselage adalah tekanan kabin. Pada pengoperasian pesawat yang terus menerus akibat tekanan kabin, damage berupa retak sering kali terjadi pada bagian fuselage. Penggunaan skin doubler untuk menangani kasus retak perlu dilakukan analisis terutama untuk melihat pengaruh ketebalan doubler dan variasi fastener terhadap kekuatan strukturnya.

Dalam penelitian ini pemodelan struktur skin doubler dan analisis menggunakan bantuan software CATIA V5R21. Pemodelan struktur dibuat 4 jenis yaitu satu struktur untuk penggunaan variasi jumlah fastener dan 3 struktur lainnya untuk perubahan ketebalan doubler. Seluruh model tersebut diberikan beban tarik dan differential pressure.

Penggunan doubler yang lebih tebal pada struktur repair akan menurunkan tegangan yang terjadi pada doubler. Semakin banyak jumlah row fastener yang digunakan akan menurunkan tegangan pada fastener hal ini terjadi pada beban tarik, tetapi belum cukup efektif untuk beban differential pressure. Struktur pemodelan ini aman terhadap pembebanan tarik dan internal pressure.
\end{abstract}

Kata kunci: Kekuatan struktur, Repair, Skin doubler. 


\section{Pendahuluan}

Fuselage merupakan bagian dari pesawat selain sebagai tempat penumpang dan barang juga sebagai bagian untuk menempatkan sayap, vertical dan horizontal tail, dan powerplant. Beban pada rancangan fuselage dihasilkan dari flight maneuver, landing atau kondisi ground handling. Beban fuselage merupakan masalah utama dalam menentukan pembagian berat, beban ekor dan beban nose landing gear. Pembagian berat penting karena sebagian besar beban fuselage bersumber dari massa inersia yang ada ketika pesawat mengalami percepatan, baik translasi dan rotasi. Salah satu pembebanan pada fuselage adalah tekanan kabin (cabin pressure).

Ada tiga kondisi jenis beban tekanan kabin yaitu:

a. Hanya berupa tekanan, di mana pesawat dirancang tanpa beban tambahan saat kondisi terbang ataupun beban landing

b. Kombinasi beban tekanan dari beban terbang, termasuk kontribusi tekanan luar dari kabin.

c. Kombinasi beban tekanan dengan beban landing.

Gaya yang bekerja pada struktur dapat menyebabkan terjadinya perubahan bentuk atau kegagalan struktur. Kegagalan struktur merupakan suatu keadaan di mana struktur tidak dapat digunakan dalam waktu yang sangat lama. Kegagalan struktur sebenarnya masih dapat diterima selama masih dalam batas pakai yang layak. Melihat pentingnya fungsi fuselage bagi sebuah pesawat, maka struktur fuselage harus dirancang dan dirawat untuk memenuhi fungsinya dengan baik guna menjamin keselamatan dan keamanan pesawat itu sendiri.

Dalam pengoperasian pesawat beberapa kasus damage sering terjadi berupa retak, korosi yang terjadi pada bagian fuselage, untuk itu perlu dilakukan repair untuk menjamin struktur tersebut layak digunakan. Untuk mengatasi hal tersebut repair dilaksanakan dengan cara memasang doubler pada bagian yang retak untuk memperkuat struktur tersebut. Petunjuk untuk melaksanakan repair sudah tercantum dalam Structure Repair Manual (SRM). Untuk melihat penerapan doubler pada struktur fuselage yang retak perlu dilakukan analisis untuk memastikan struktur tersebut aman sekaligus untuk mengetahui pengaruh ketebalan doubler dan jumlah fastener terhadap kekuatan struktur repair tersebut.

\section{Kajian Pustaka}

Besarnya persentase beban (load transfer) yang diterima oleh rivet pada sambungan plat tergantung dari jumlah rivet yang digunakan serta bentuk susunan assembly/rivet joint (Iryani, 2009). Pada penelitian ini diperoleh hasil semakin banyak rivet yang digunakan load transfer yang diterima setiap rivet semakin kecil.

Analisis penggunaan tipe rivet lap joint menunjukkan bahwa penggunaan susunan zigzag riveting menghasilkan tegangan geser yang lebih rendah dibandingkan dengan susunan chain riveting (Suyogkumar, 2013). Pada penelitian ini pemodelan part menggunakan CATIA V5R20, analisis rivet menggunakan software ANSYS. Pada pemasangan tipe chain riveting nilai tegangan geser dengan tegangan geser maksimumnya tidak jauh berbeda.

Pada kedua penelitian tersebut struktur pemodelan merupakan tipe susunan pemasangan rivet yang melibatkan skin dan rivet, sedangkan pada penelitian ini selain kedua struktur tersebut ditambahkan model retak, filler yang diperkuat doubler, serta penggunaan variasi ketebalan doubler. 
Rivet joint atau fastener adalah suatu pin yang digunakan untuk menghubungkan dua atau lebih dari sheet metal, plate ataupun aircraft part. Part pesawat di-assembly dengan menggunakan rivet di mana bentuk riveted joint pada konstruksi pesawat umumnya dibagi menjadi 2 kelompok, yaitu:

\section{A. Riveted lap loint}

Part yang di-assembly diatur sedemikian rupa, sehingga posisi satu part dengan part lainnya saling menutupi sebagian dari permukaannya (overlapped). Riveted lap joint dibagi menjadi 2 macam yaitu :

1. Single riveted lap joint

2. Double riveted lap joint
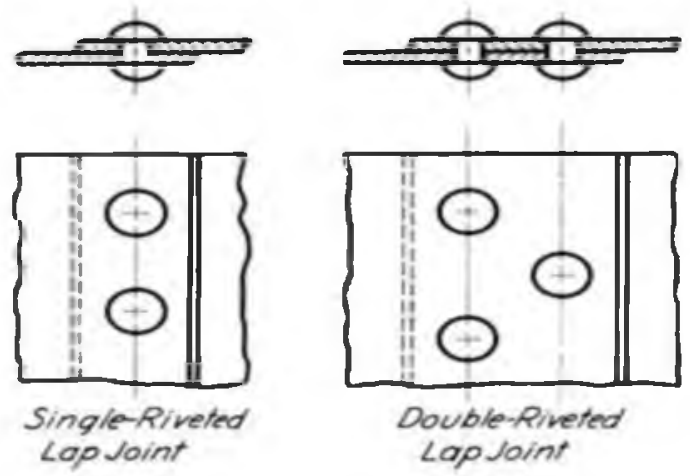

Gambar 1. Riveted lap joint

\section{B. Strap butt joint}

Riveted joint ini memerlukan suatu part tersendiri (strap) untuk menggabungkan kedua ujung part yang terpisah.Pengaturan strap dalam riveted joint ini digolongkan seperti berikut:

1. Single strap butt joint

2. Double strap butt joint
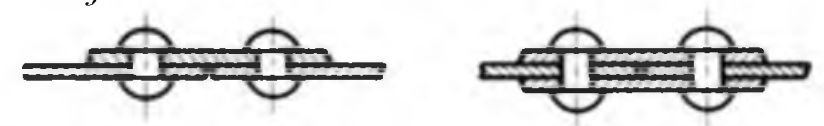

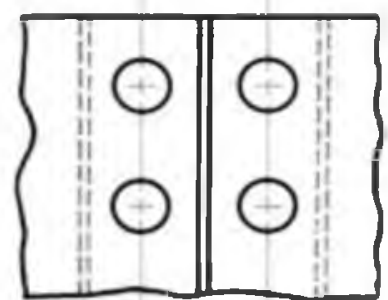

Single-Riveted Single Strap Butt Joint

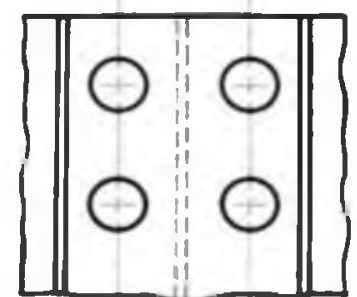

Single-Riveted Double Strop Butt Joint

Gambar 2. Strap butt joint

Salah satu metode yang digunakan untuk menentukan kekuatan struktur dalam pesawat adalah menggunakan perhitungan batas keamanan (margin of safety $M S$ ). $M S$ merupakan ukuran besarnya kemampuan atau kapasitas yang masih tersedia dalam suatu struktur untuk menerima beban statik secara aman pada kondisi pembebanannya. 
Dalam bentuk tegangan persamaan $M S$ adalah:

$$
\text { Margin of Safety }(M S)=\frac{\sigma_{a l l}}{\sigma_{a p p}}-1 \geq 0
$$

\section{Metodologi Penelitian}

Pada penelitian ini struktur yang akan dimodelkan adalah struktur skin fuselage pesawat B737-300 yang mengalami retak. Struktur tersebut terletak pada station 500A sampai 500B pada posisi stringer $17 \mathrm{~L}$ sampai $18 \mathrm{~L}$ (sebelah kiri). Adanya retak tersebut perlu dilakukan repair dengan melakukan cut out pada skin serta menambah filler dan doubler yang dimensinya akan tergantung dari fastener yang digunakan.

Struktur model menggunakan bentuk seperempat dari struktur aslinya dengan dimensi sebagai berikut :

Dimensi Skin: panjang 10 in, lebar 5,8 in, tebal 0,036 in.

Fastener yang digunakan: BACR15BB6D diameter 0,187 in, BACR15BB6AD diameter 0,187 in.

Dimensi Doubler: panjang 4,914 in, lebar 4,582 in, tebal divariasikan.

Dimensi retak: panjang 1,029 in, lebar 1,122 in dengan radius 0,5 in.

Material yang digunakan:

Aluminum 2024-T3: skin dan doubler

Aluminum 2017-T4: fastener BACR15BB6D

Aluminum 2117-T4: fastener BACR15BB6AD
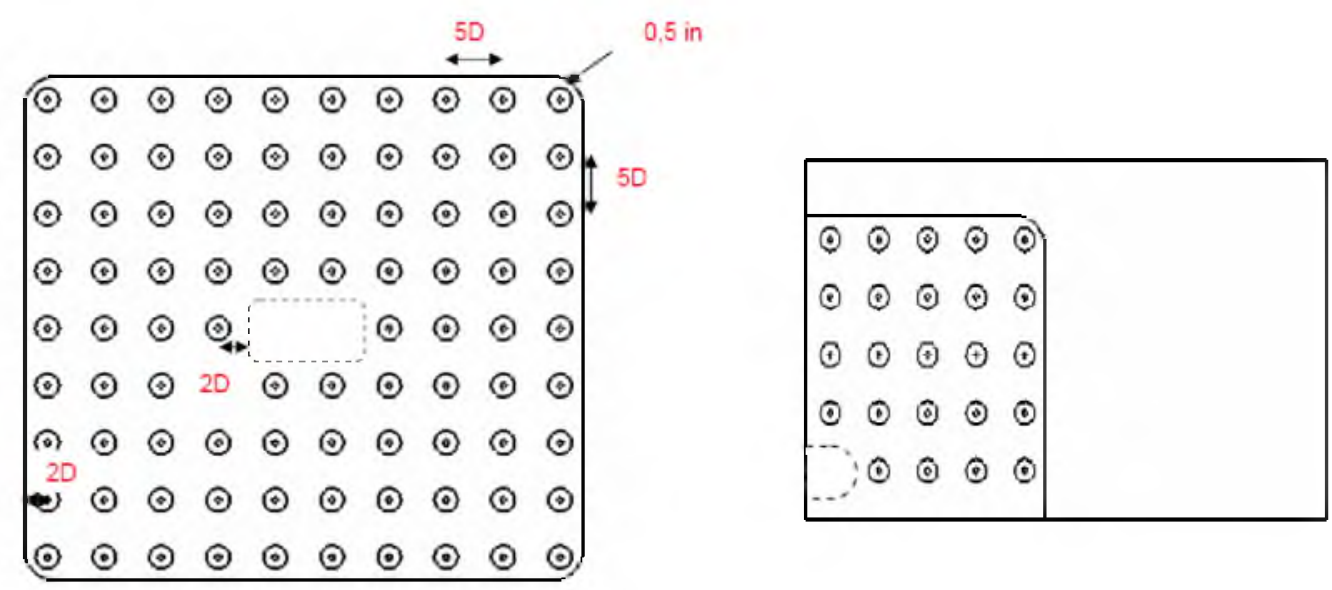

Gambar 3. Model doubler repair utuh dan seperempat

Pemodelan struktur terdiri 4 macam:

- Model 1: struktur skin doublerdengan jumlah fastener 3 row dan tebal doubler 0,05 in.

- Model 2: struktur skin doubler dengan jumlah fastener 4 row dan tebal doubler 0,045 in.

- Model 3 : struktur skin doubler dengan jumlah fastener 4 row dan tebal doubler 0,05 in.

- Model 4: struktur skin doubler dengan jumlah fastener 4 row dan tebal doubler 0,063 in. 
Beban yang digunakan pada kasus ini ada 2 macam :

- Beban differential pressure 7,8 Psi asumsi pesawat terbang pada ketinggian $37.000 \mathrm{ft}$ (menggunakan diagram nomogram).

- Beban tarik yang digunakan berdasarkan pendekatan, diasumsikan sama dengan perbedaan tekanan kabin dikalikan luas model sebesar 452,4 lbf.

Pemodelan dan analisis struktur menggunakan software CATIA V5R21, dari hasil analisis akan ditentukan respon struktur dalam bentuk tegangan maksimum. Langkah selanjutnya menghitung margin of safety (MS) untuk mengevaluasi pengaruh ketebalan doubler dan jumlah fastener yang digunakan terhadap kekuatan strukturnya.

\section{Metodologi Penelitian}

\subsection{Kasus Beban Tarik}

Pada model 1, beban tarik diterapkan pada bagian sebelah kanan permukaan skin. Jenis restraint yang digunakan adalah user-defined restraint pada 2 permukaan. Nilai tegangan maksimum von mises adalah 4638,19 Psi, terletak pada fastener bagian tepi doubler. Sedangkan nilai margin of safety adalah 8,628 dari perhitungan berikut :

$$
M S=\frac{24000 P s i}{4638,19 P_{s i}}-1=5,17
$$

Pada model 2 tegangan maksimumnya sebesar 4056,28 Psi, terletak pada skin bagian dalam, besar nilai $M S$ adalah 12,33 .
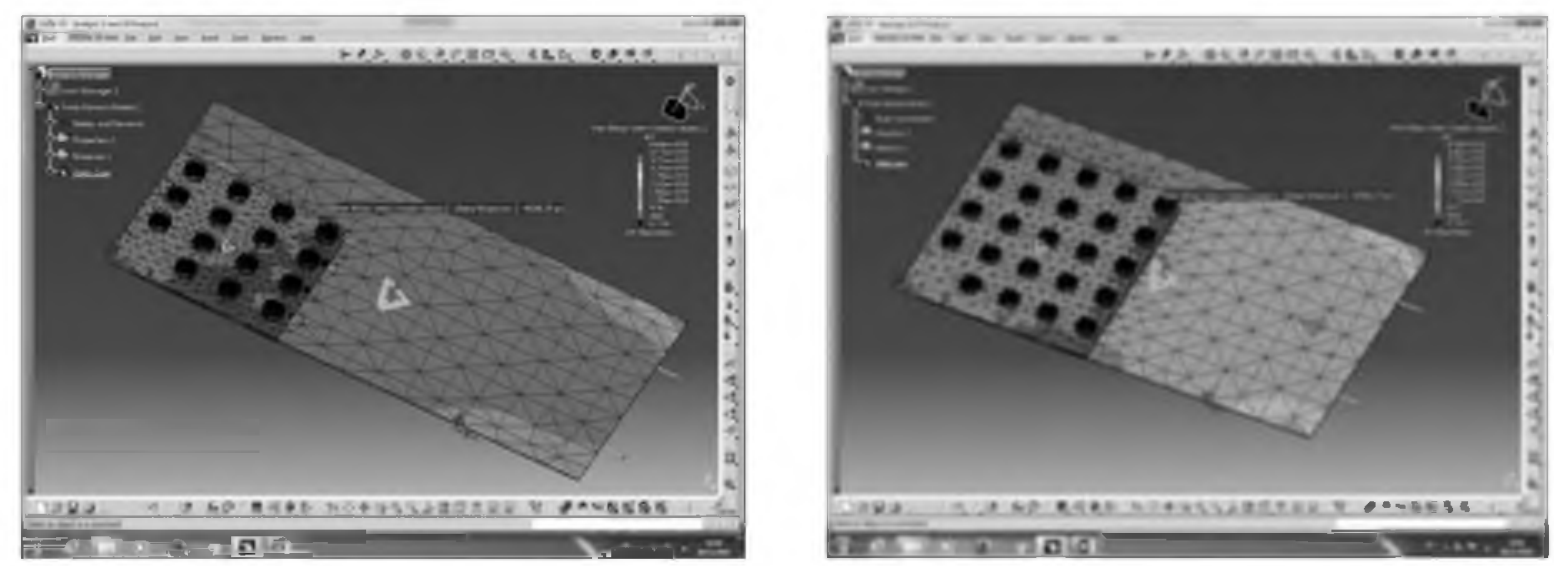

Gambar 4. Nilai tegangan maksimum von mises model 1 dan 2

Pada model 3 tegangan maksimumnya sebesar 4220,79 Psi, terletak pada skin bagian dalam fastener seperti gambar 7, dengan nilai $M S$ adalah 11,85. Model 4 tegangan maksimum 4259,39 Psi, terletak pada bagian yang sama dengan model 3, dengan nilai $M S$ 11,74. Besarnya nilai tegangan maksimum dan $M S$ tercantum pada tabel 1. 

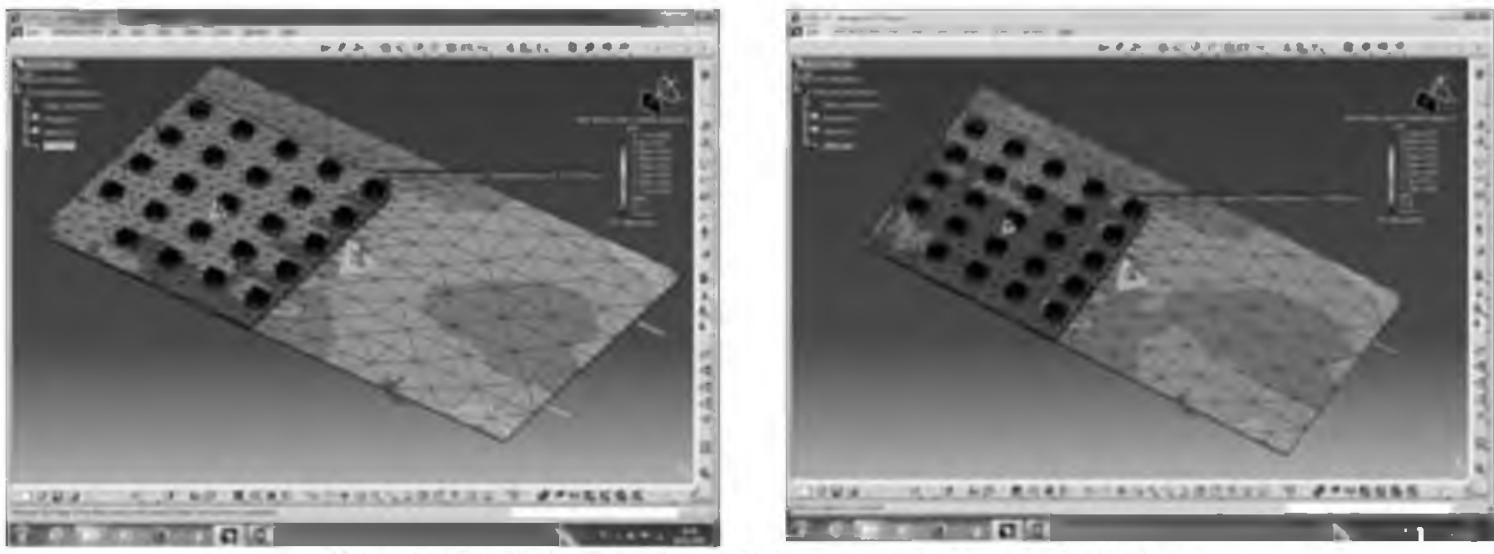

Gambar 5. Nilai tegangan maksimum von mises model 3 dan 4

Tabel 1. Data tegangan maksimum pada beban tarik

\begin{tabular}{llccc}
\hline Sampel & Part & $\begin{array}{c}\text { Tegangan } \\
\text { Maksimum (Psi) }\end{array}$ & $\begin{array}{c}\text { Yield Strength } \\
\text { (Psi) }\end{array}$ & Margin of Safety \\
\hline \multirow{3}{*}{ Model 1 } & Skin & 4081,84 & 50000 & 12.35 \\
& Doubler & 2321,12 & 50000 & 21.54 \\
& Fastener & $\mathbf{4 6 3 8 , 1 9}$ & 24000 & 5.17 \\
\hline \multirow{3}{*}{ Model 2 } & Skin & $\mathbf{4 0 5 6 , 2 8}$ & 50000 & 12.33 \\
& Doubler & 1959,95 & 50000 & 25.51 \\
& Fastener & 3602,7 & 24000 & 6.66 \\
\hline \multirow{3}{*}{ Model 3 } & Skin & $\mathbf{4 2 2 0 . 7 9}$ & 50000 & 11.85 \\
& Doubler & 1846.98 & 50000 & 27.07 \\
& Fastener & 3664.18 & 40000 & 10.92 \\
\hline \multirow{3}{*}{ Model 4 } & Skin & $\mathbf{4 2 5 9 . 3 9}$ & 50000 & 11.74 \\
& Doubler & 1774.26 & 50000 & 28.18 \\
& Fastener & 3181.28 & 24000 & 7.54 \\
\hline
\end{tabular}

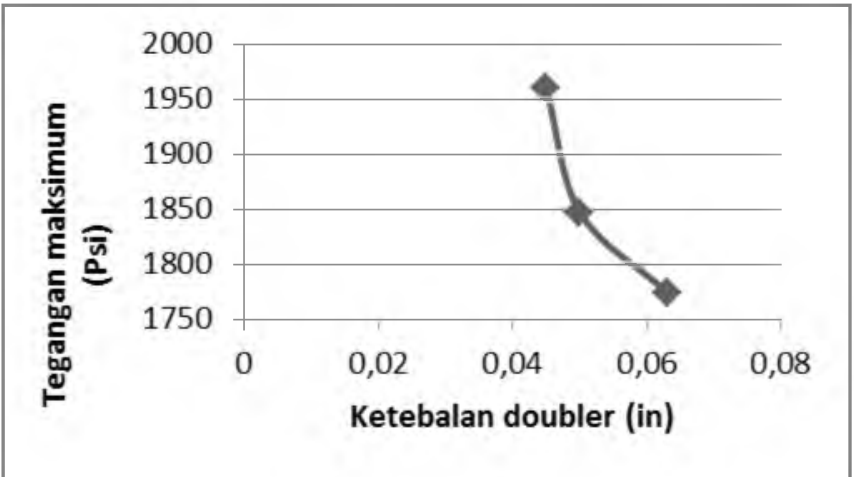

Gambar 6. Grafik ketebalan doubler terhadap tegangan maksimum doubler

Dari hasil analisis tegangan, terlihat bahwa semakin tebal dimensi doubler maka tegangan yang terjadi pada doubler tersebut akan cenderung turun hal ini karena semakin tebal doubler struktur semakin kaku sehingga lebih kuat untuk menahan beban tarik. Namun pada kondisi yang sama tegangan yang terjadi pada skin semakin meningkat, hal ini akibat kekakuan yang semakin membaik pada doubler menyebabkan sebagian gaya ditransfer ke bagian skin yang lebih tipis. 
Pada model 1 bila dibandingkan dengan model 2,3,4 yang mempunyai jumlah fastener lebih banyak, memiliki tegangan yang lebih tinggi. Hal ini karena fastener sebagai pengikat skin dan doubler akan mentransfer beban dari skin ke doubler. Jumlah fastener yang lebih sedikit pada model 1 akan menerima beban yang lebih besar dibandingkan dengan ketiga model.

Dari pemodelah seluruh part nampak bahwa nilai margin safety-nya lebih besar dari nol sehingga struktur tersebut aman untuk digunakan.

\subsection{Kasus Beban Differential Pressure}

Pada kasus ini beban differential pressure sebesar 7,8 Psi diterapkan pada seluruh surface struktur. Jenis restraint menggunakan clamp pada surface bagian atas dan sisi kanan skin. Pada model 1 nilai tegangan maksimumnya adalah 12264,3 Psi terletak pada skin dekat clamp bagian atas, sedangkan nilai $M S$ adalah 4,4. Hal ini terjadi karena model di-clamp pada kedua sisi skin, struktur tersebut mirip batang kantilever, sehingga momen maksimum akibat beban pressure terjadi di daerah dekat clamp yang akan menimbulkan tegangan yang lebih besar.

Pada model 2, 3 dan 4 kecenderungannya juga mengikuti pola yang sama dengan model 1. Tegangan maksimumnya terletak pada fastener bagian pinggir doubler dekat dengan clamp.
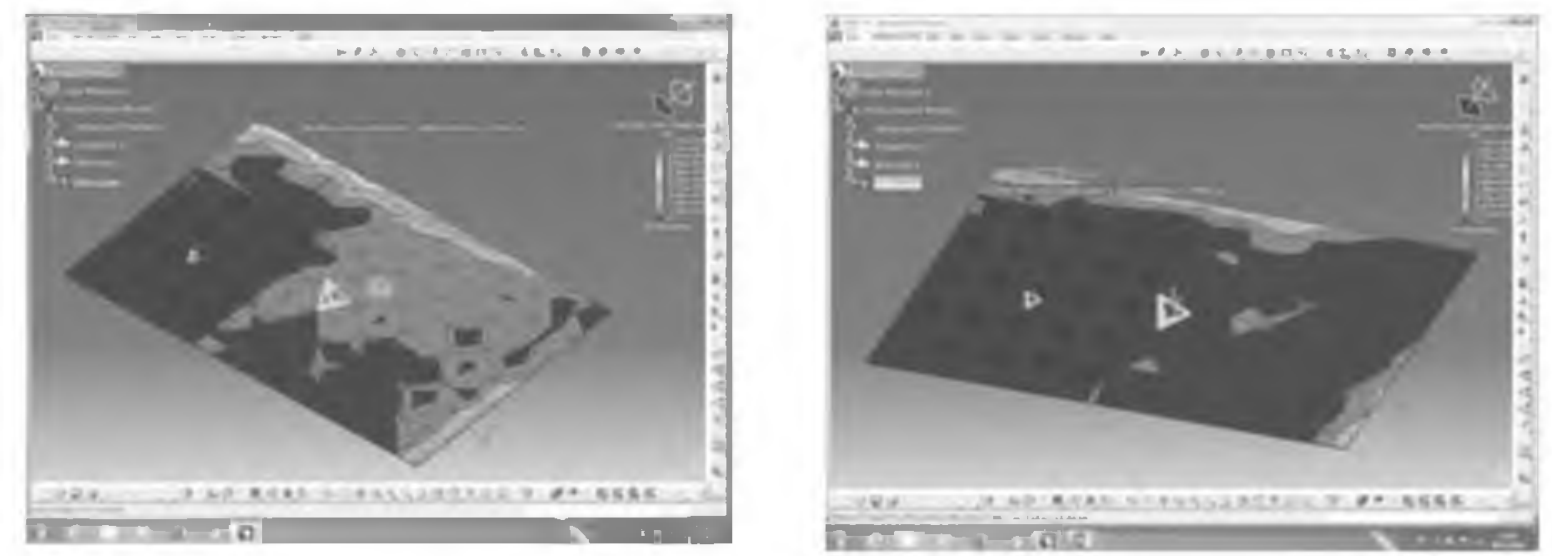

Gambar 7. Nilai tegangan maksimum von mises model 1 dan 2
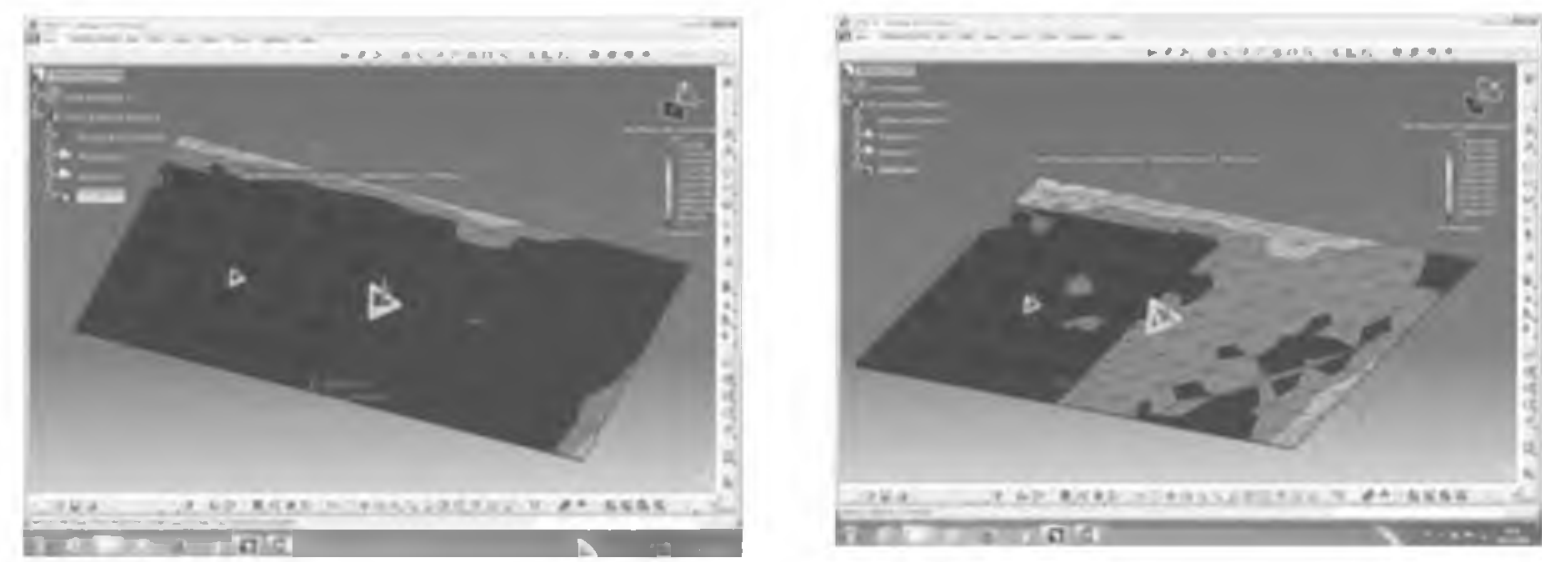

Gambar 8. Nilai tegangan maksimum von mises model 3 dan 4 
Tabel 2. Data tegangan maksimum pada beban differential pressure

\begin{tabular}{llccc}
\hline Sampel & Part & $\begin{array}{c}\text { Tegangan } \\
\text { Maksimum (Psi) }\end{array}$ & $\begin{array}{c}\text { Yield Strength } \\
\text { (Psi) }\end{array}$ & $\begin{array}{c}\text { Margin of } \\
\text { Safety }\end{array}$ \\
\hline \multirow{2}{*}{ Model 1 } & Skin & $\mathbf{1 2 2 6 4 . 3}$ & 65000 & 4.08 \\
& Doubler & 2573.26 & 65000 & 19.43 \\
& Fastener & 9638.94 & 24000 & 2.49 \\
\hline \multirow{2}{*}{ Model 2 } & Skin & 15596 & 50000 & 3.21 \\
& Doubler & 7562.61 & 50000 & 6.61 \\
& Fastener & $\mathbf{2 7 0 8 8 . 2}$ & 24000 & 0.89 \\
\hline \multirow{3}{*}{ Model 3 } & Skin & $\mathbf{2 9 9 6 9}$ & 50000 & 1.67 \\
& Doubler & 5583.83 & 50000 & 8.95 \\
& Fastener & 12922.5 & 24000 & 3.10 \\
\hline \multirow{3}{*}{ Model 4 } & Skin & $\mathbf{1 5 6 1 2 . 9}$ & 50000 & 3.20 \\
& Doubler & 4208.62 & 50000 & 11.88 \\
& Fastener & 11066.5 & 24000 & 2.17 \\
\hline
\end{tabular}

Pada model 2,3,4 dengan tebal doubler yang meningkat, tegangan yang terjadi pada doubler juga cenderung turun seperti kasus beban tarik, hal ini menunjukkan struktur yang lebih tebal akan semakin kaku sehingga lebih baik dalam menahan beban.

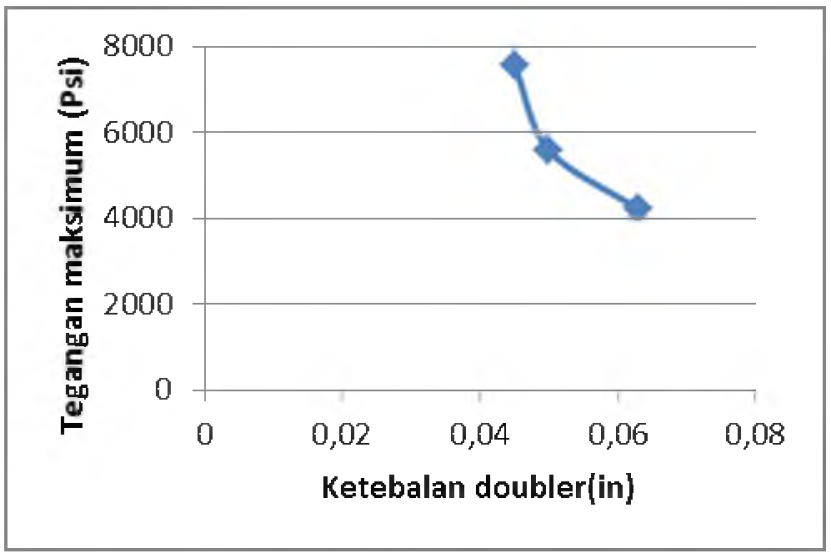

Gambar 9. Grafik ketebalan doubler terhadap tegangan maksimum doubler

Penggunaan jumlah fastener yang lebih banyak pada model 2,3,4 tidak menunjukkan turunnya tegangan akibat beban differential pressure. Hal ini kemungkinan pemodelan seperempat yang di-clamp pada kedua surface, ada bagian struktur yang bebas (kantilever) pada saat dibebani fastener belum cukup efektif mentransfer beban ke fastener yang lain.

Secara keseluruhan struktur keempat model aman terhadap beban differential pressure yang ditunjukkan nilai $M S$ positif. 


\section{Kesimpulan}

Dari hasil analisis yang dilakukan pada penelitian ini, diperoleh kesimpulan sebagai berikut:

1. Penggunan doubler yang lebih tebal pada struktur repair akan menurunkan tegangan yang terjadi pada doubler, sehingga kekuatan strukturnya menjadi lebih baik.

2. Semakin banyak jumlah row fastener yang digunakan akan menurunkan tegangan pada fastener hal ini terjadi pada beban tarik, tetapi belum cukup efektif untuk beban differential pressure.

3. Struktur pemodelan skin doubler aman terhadap pembebanan tarik dan differential pressure berdasarkan nilai margin safety.

\section{Daftar Pustaka}

Arumulla, Suresh \& Tippa Bhimasankara, 2013, "Analysis of Rivet Using Finite Element Analysis”, International Journal of Computational Engineering Research, Vol. 2, Issue 4, 2013.

Boeing 737-300, “Structure Repair Manual”, Chapter 51-00-00, 51-20-01, 51-20-06, 51-3001,53-60-5.

D. Cook, Robert, 1981, "Concept and Applications of Finite Element Analysis", John Wiley \& Sons.

Iryani, Leni, 2009, “Analysis Of Riveted Joint Using Vlieger/Broek Equation”, Jurnal Tekno Insentif 09, Volume 3 Nomor 1, Juli 2009.

Karthik N\&Anil Kumar, 2013, Analysis of the Fuselage Structure for Multi Site Damage,International Journal of Innovative Research in Science, Engineering and Technology, Vol. 2, Issue 7, July 2013.

M. Santosh Kumar1, 2015, "Analysis of Double Riveted Single Lap Joint in Laminated FRP Composites Subjected to Transverse Loading", Journal of Material Science and Mechanical Engineering (JMSME), Volume 2, Number 3; April-June, 2015.

Niu CY, Michael, 1988, “Airframe Structural Design”, Hong Kong Conmilit Press Limited.

Niu CY, Michael, 1997, “Airframe Stress Analysis and Sizing”, Hong Kong Conmilit Press Limited.

Suyogkumar W. Balbudhe dkk, 2013, Stress Analysis Of Various Tipes Of Riveted Lap Joint, International Journal of Mechanical and Robotic Research (IJMERR), Volume 2 No 4 , October 2013. 
Djarot Wahju Santoso 